\title{
Performance Analysis of DC-DC Converters for Solar Water Pumping System Employing Switched Reluctance Motor Drive
}

\author{
T.Sai Rakshitha, E.Shiva Prasad , K.Sravani
}

\begin{abstract}
The grail of this paper is to investigate the performance of various DC-DC converters for solar based water pump system incorporating switched reluctance motor drive. The Converters used are CUK converter, Buck-Boost converter and Boost converter respectively. The speed of the switched reluctance motor is regulated by the mid-point converter along with the various DC-DC converters. The Switched reluctance motor is adopted over other motors because of its low inertia, ease of control, speed range is wide, less losses as there is no windings nor permanent magnets Present on the rotor. In order to operate the solar PV array at its optimum level we employ maximum power point tracking (MPPT) and specifically Perturb and Observe control method is employed in this project. The proposed system deals with the design, modeling and simulation of three different types of converters using MATLAB/Simulink environment. The applicability of this system can be analyzed by the simulated results.
\end{abstract}

Keywords: Maximum power point tracking (MPPT), Photovoltaic System, Switched Reluctance Motor (SRM).

\section{INTRODUCTION}

India is one of the subtropical countries which have about 2000 hours to 3000 hours of sunshine throughout the year; these lands can use the solar energy for generation of power. The solar water pump is one of the applications of solar energy which is very useful for agriculture. The continuity of water supply is difficult in areas where there is no pipe line but has water underground in deep wells. Solar water pump is one of the most preferred applications of solar energy. Profuse motors are used so far in water pumping system using solar energy. There are lot of complications in using direct current and alternating current motors among which dc motors usage involves lot of maintenance of brushes along with commutators, whereas ac motors face difficulties to run

Revised Manuscript Received on January 05, 2020.

* Correspondence Author

T.Sai Rakshitha*,Department of Electrical Engineering, VNR VJIET, Hyderabad, India .Email: sairakshitha14@gmail.com

E.Shiva Prasad, Department of Electrical Engineering, VNR VJIET, Hyderabad, India . Email: shivaprasad_e@vnrvjiet.in

K.Sravani,. Department of Electrical Engineering, VNR VJIET, Hyderabad, India . Email: sravani_k@vnrvjiet.in at low speeds and has complex control. The Switched reluctance motor has elementary construction [12].

The SRM has low inertia,ease in control, extended speed range and less overall cost. The other advantage of SRM is that the stator windings are separated electrically which makes the converter topology and controlling flexible when compared with other drives.

The two conventional topologies of solar powered water pump system is by employing boost converter along with battery and the other one is battery voltage regulator. Both of these methods have drawbacks like reduce efficiency, reliability due to the change in operating voltage level due to the battery regulation. The proposed system deals with the inquiry of various types of DC-DC converters suitable for solar water pump application. The performance is inquired by using MATLAB /Simulink environment.

\section{FRAME WORK OF PROPOSED SYSTEM}

The proposed topology of solar powered water pump system is shown in Fig.1, which is basically the block diagram. Three different DC-DC converters used namely Boost, Buck-Boost, CUK. The midpoint converter feeds the SRM which is intern coupled to a centrifugal pump. The performance of various converters is discussed elaborately.

\section{CONTROL TECHNIQUES OF THE SYSTEM}

In this system perturb and observe is the algorithm used for tracking the maximum amount of power from the photovoltaic array and the converter which the SRM is controlled by using electronic commutation which is by using hall sensors.

\section{A. MPPT Control Technique}

The MPP always varies with the changes in the temperature and irradiance levels. These changes need to be tracked time to time, therefore different algorithms need to be used for this process among which in this system Perturb and Observe technique is employed [7].

This method is usually preferred because of its less complexity for implementation.

This method varies the duty ratio of the converters through the MPPT control algorithm and thus generates the PWM pulses which are required for switching on the switches of the converter. 


\section{B. SRM Conduction Angle Control}

The method used to get the smooth control, ripple free torque and improved efficiency is by using control techniques on to the rotor position. It is done by using position sensors.

The control happens mainly with the help of two angles namely turn-on angle $\left(\theta_{\alpha}\right)$ and turn-off angle $\left(\theta_{\beta}\right)$ [9].

The switches of each phase need to be turned on once for every 45 degrees. The $\theta_{\alpha}$ should be chosen in such a way that it allows the growth of the current which intern reduces the inductance value to a minimum level.

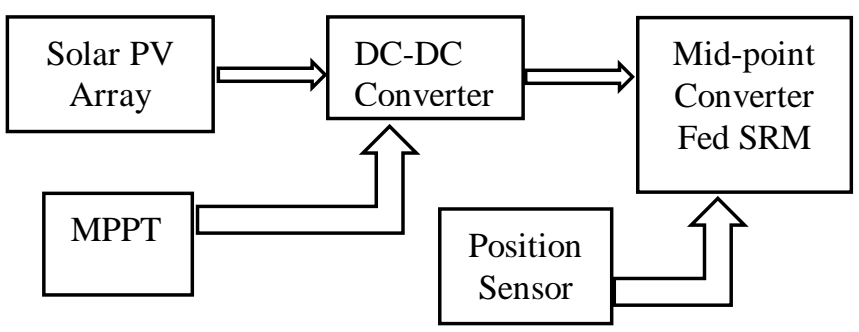

Fig. 1. The proposed topology block diagram

\section{PROPOSED SYSTEM DESIGN}

In the proposed system designing consists of components design of the Boost, Buck-Boost and Cuk converters. It also contains design of PV array and SRM.

\section{A. Solar PV Array}

The system peak power rating is $4.5 \mathrm{~kW}$. The short circuit current of the module is $8.5 \mathrm{~A}\left(I_{s c}\right)$ and open circuit voltage of the module is $30 \mathrm{~V}$ ( $V_{\text {ocm }}$ ).

The current and voltage values per module are $7.5 \mathrm{~A}\left(I_{M P}\right)$ and $25 \mathrm{~V}\left(V_{M P}\right)$ respectively. The open circuit array voltage of PV panel is $310 \mathrm{~V}$ ( $\left.V_{O C P}\right)$. The strings to be connected in series is given by the following equation,

$$
V_{\text {OCP }}=n_{g} * V_{\text {ocm }}
$$

Thus there are 15 modules per series string. The strings that are connected in parallel is given by

$$
I_{M P}=n_{p} * I_{g e}
$$

Thus there are 2 modules per each parallel string. Thus the PV array totally contains $2 * 15$ modules [3-5].

\section{B. CUK Converter Design}

The CUK converter basically has two inductors along with a capacitor. The schematic diagram of CUK converter based water pump is shown in Fig. 2 .

The duty ratio is calculated by the following equation as,

$$
\frac{V_{d e}}{V_{M P P}+V_{d e}}=0.659
$$

Input inductance is as follows,

$$
L_{1}=\frac{V_{M P P} * D}{\Delta I_{1} * f S W}=4.5397 \mathrm{mH}
$$

(4)

Output inductance is as show below,

$$
L_{2}=\frac{V_{d c} *(1-D)}{\Delta I_{2} * f S W}=9.742 \mathrm{mH}
$$

The value of capacitance is estimated as,

$$
C_{1}=\frac{I_{1} *(1-D)}{\Delta V_{C 1} * f S W}=2.89 \mu \mathrm{F}
$$

$f_{\text {SW }}$ denotes the switching frequency which is chosen to be $15 \mathrm{KHz}$.

The $\Delta V_{c 1}, \Delta I_{1}, \Delta I_{2}$ are the respective allowable voltage and current ripples.

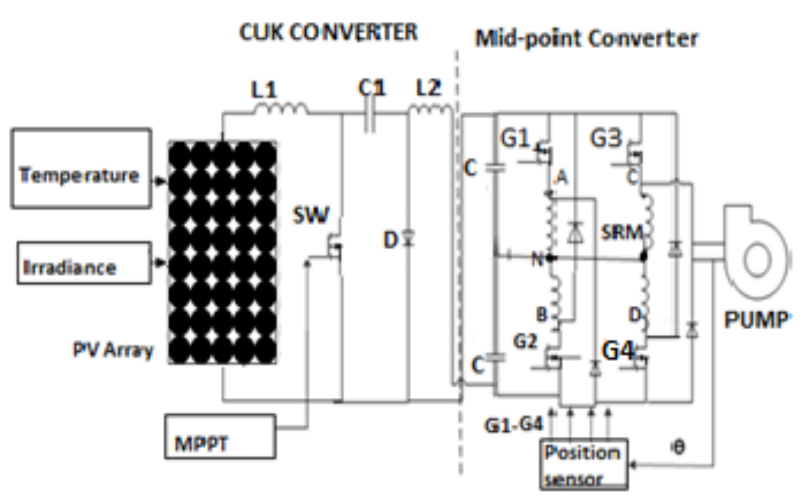

Fig. 2. Schematic Diagram of CUK Converter Based Water Pump

\section{Buck-Boost and Boost Converter Design}

The Buck-Boost converter and the boost converter has same design parameters which consists of inductor and capacitors and the Fig. 3 and Fig. 4 represents the schematic diagram of the two converters based water pump.

The duty ratio is as shown below,

$$
\frac{V_{d c}}{V_{M P P}+V_{d i c}}=0.659
$$

The inductor value is estimated as

$$
\mathrm{L}=\frac{V_{M P P} * D}{\Delta I_{L} * f S W}=5.4477 \mathrm{mH}
$$

The capacitance value is given as,

$$
C_{1}=C_{2}=\frac{I *(30-\alpha)}{2 * \Delta V_{d i} * w}=3.21 \mu \mathrm{F}
$$




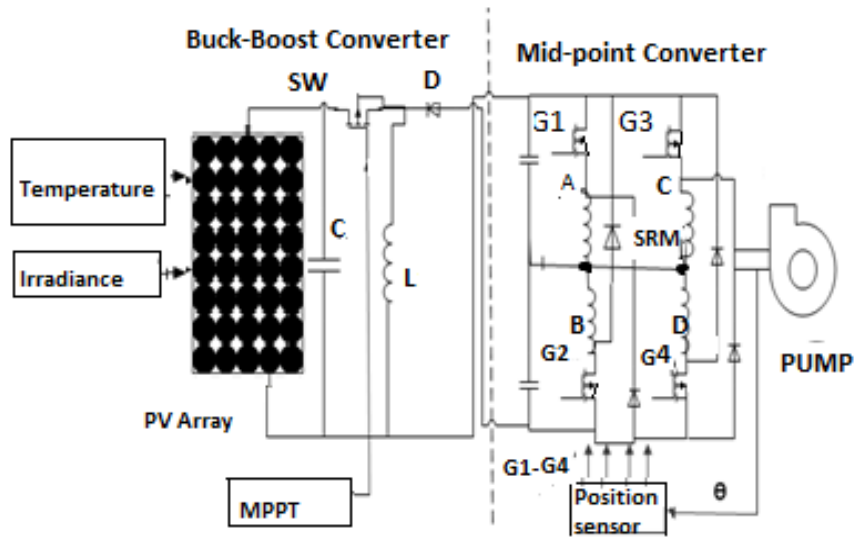

Fig. 3. Schematic Diagram Representation of Buck-Boost Converter Based Water Pump

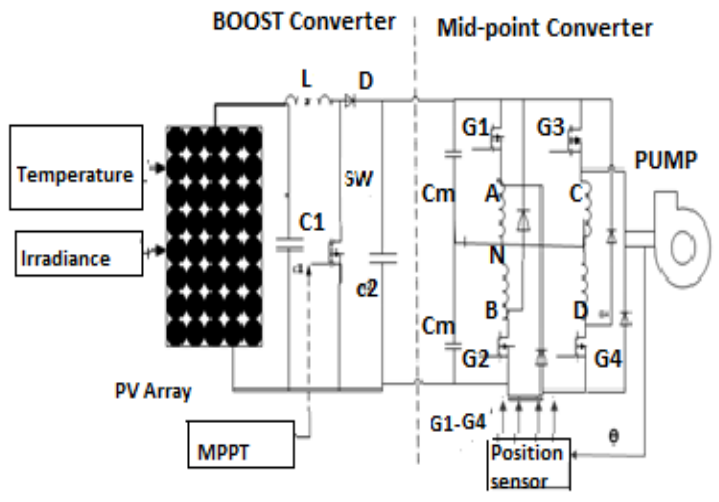

Fig. 4. Schematic Diagram Representation of Boost Converter Based Water Pump

\section{Modeling and Design of SRM}

The basic equivalent circuit of SRM is shown in Fig.5 which is modeled by considering current-controlled voltage source. The specifications of SRM are $3.5 \mathrm{~kW}, 8 / 6$ pole, 1500 rpm.

The following equation gives the KVL equation of SRM in the conducting phase as,

$$
\begin{gathered}
V=R * I+\frac{d \Psi}{d t} \\
V=R * I+L * \frac{d i}{d t}+w_{m} * i * \frac{d i}{d t}
\end{gathered}
$$

Where the term $V$ represents the voltage at terminals .

Generally the last term in the above equation can be also given as,

$$
\mathrm{E}=w_{m} * i * \frac{d i}{d \theta}
$$

By interpreting the instantaneous electrical and mechanical powers we can obtain the torque developed across the terminals of the motor.

$$
\mathrm{T}=\frac{1}{2} * I^{2} * \frac{d L}{d g}
$$

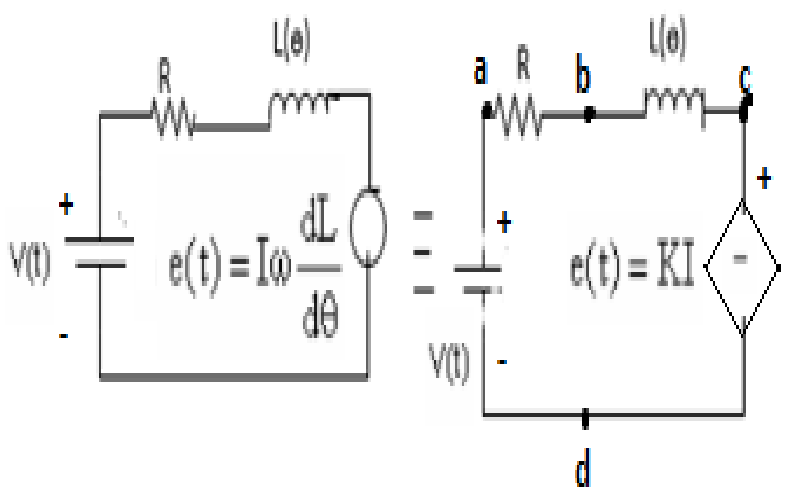

Fig. 5. Equivalent circuit of SRM

\section{PROPOSED SYSTEM DESIGN}

The solar powered water pump system using three different converters is designed as discussed in the above sections and it is simulated using MATLAB/Simulink.

The performance is analyzed based upon the speed of the SRM and the torque developed in the SRM. The solar panels are operated at a fixed irradiance of $1000 \mathrm{~W} / \mathrm{m}^{2}$ and the operating temperature is $25^{\circ} \mathrm{C}$.

\section{A. Performance of solar powered Water Pump using CUK Converter}

Fig. 6 shows the voltage waveform of Cuk converter which is $605 \mathrm{~V}$.

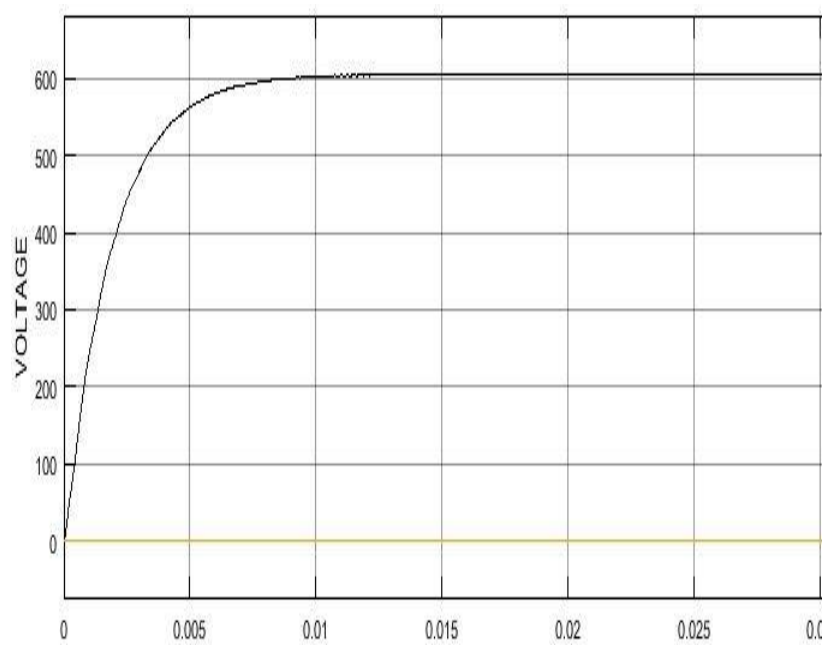

Fig. 6. Voltage Waveform of CUK converter

Fig.7 shows the speed with the SRM is operating which is given as the input to centrifugal pump and it also shows the developed torque in the motor. The speed value is $1500 \mathrm{rpm}$ and the torque obtained is $24 \mathrm{~N}-\mathrm{m}$. 

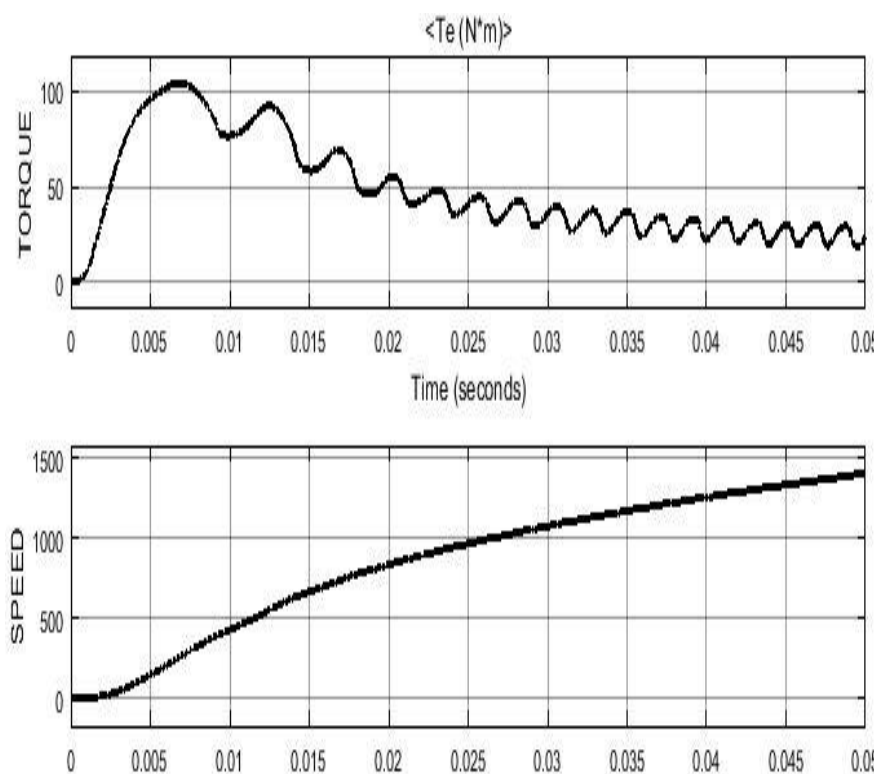

Fig. 7. Speed and Torque of SRM Employing CUK Converter

B. Performance of solar powered Water Pump using Boost Converter

Fig. 8 denotes the terminal voltage of the Boost converter whose value is $600 \mathrm{~V}$.

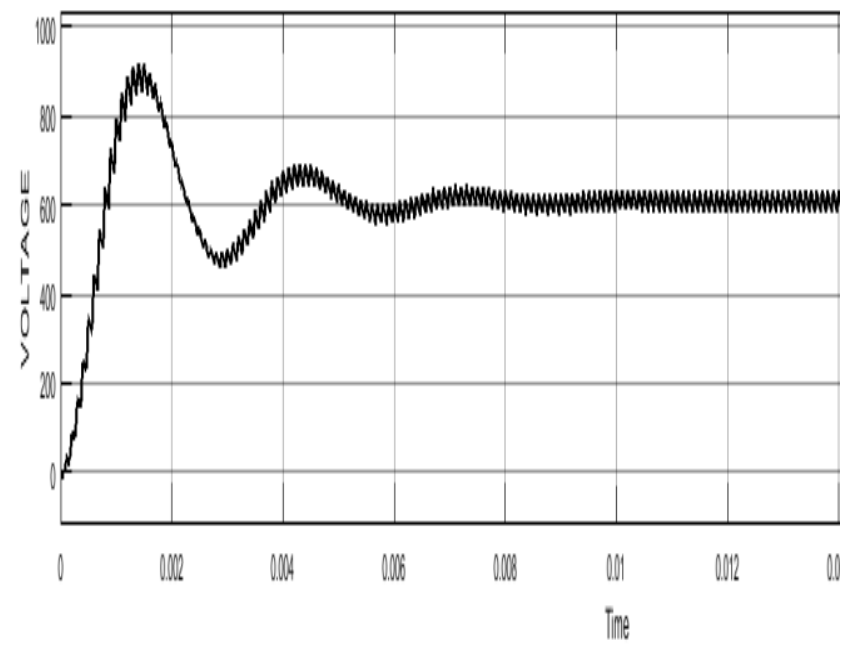

Fig. 8. Voltage Waveform of Boost Converter

Fig.9 shows the speed with which the SRM is operating and also it gives us the developed torque value. The speed with the SRM is running is $1280 \mathrm{rpm}$ and the torque developed in the motor id $20 \mathrm{~N}-\mathrm{m}$.

\section{Performance of solar powered Water Pump using Buck-Boost Converter}

Fig.10 represents the terminal voltage of buck-boost converter and its voltage value is $600 \mathrm{~V}$.
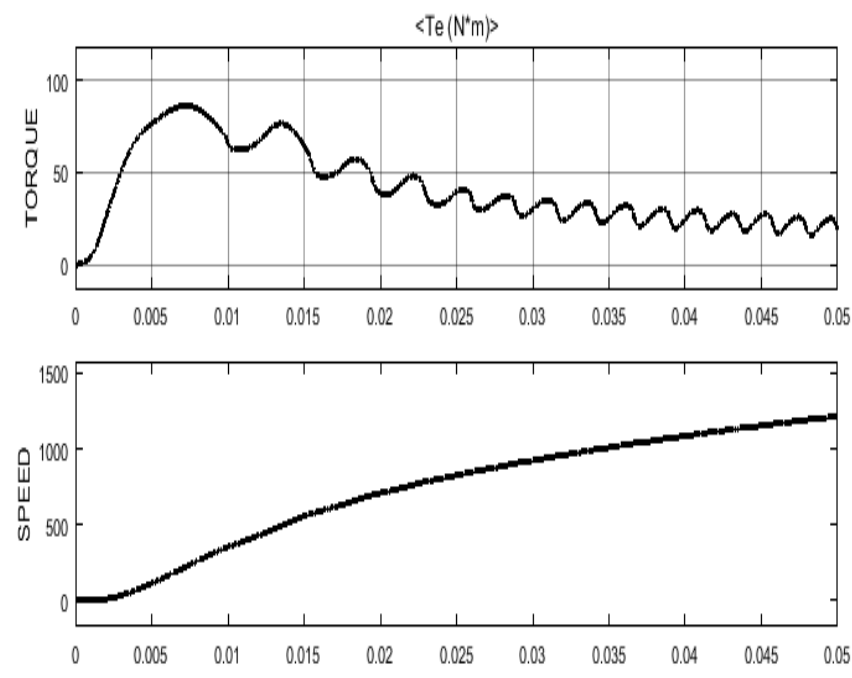

Fig. 9. Speed and Torque of SRM Employing Boost Converter

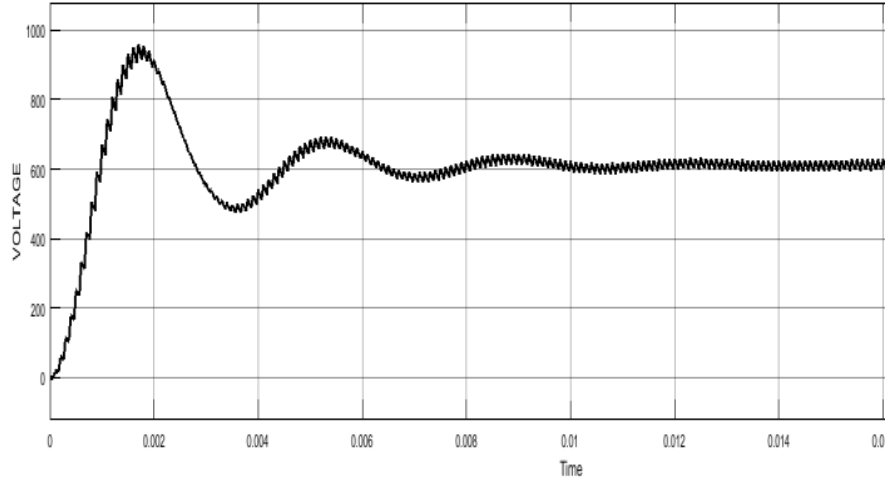

Fig. 10. Voltage Waveform of Buck-Boost Converter

Fig.11 shows the speed with which the SRM is operating and also the torque developed in the motor. The speed with which the SRM is operating is $1270 \mathrm{rpm}$ and the torque developed is $19.7 \mathrm{~N}-\mathrm{m}$.
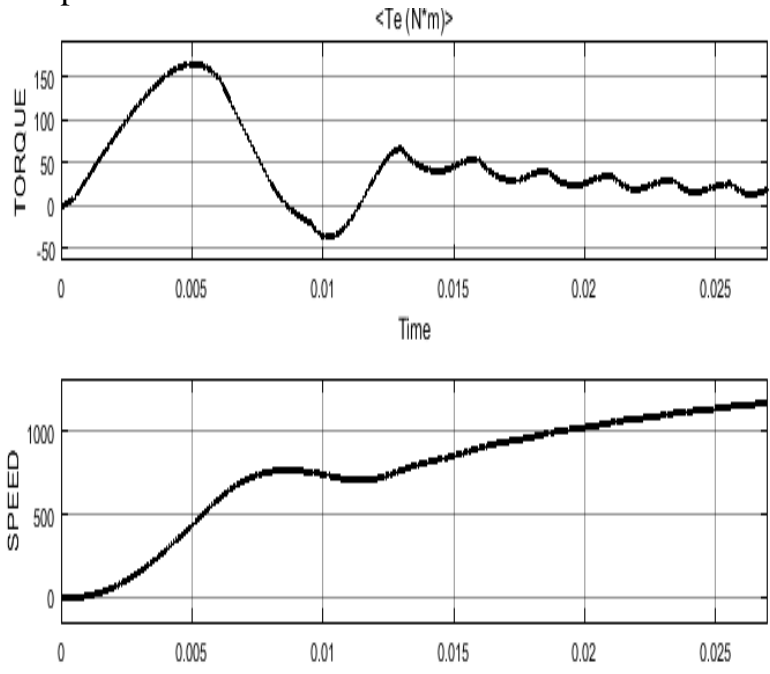

Fig. 11. Speed and Torque of SRM Employing BuckBoost Converter

\section{CONCLUSION}

The solar powered water pump system incorporating SRM along with three different converters is simulated using MATLAB/Simulink.

Following are the conclusions 
and observations obtained from the results:

- The operation of switches in the mid-point converter employing electronic commutation results in the improvement of efficiency.

- The below table gives the comparison of the performance between the three different converters with respect to speed and torque:

\begin{tabular}{|c|c|c|}
\hline Converter & $\begin{array}{c}\text { Speed } \\
(\mathrm{rpm})\end{array}$ & $\begin{array}{c}\text { Torque } \\
(\mathrm{N}-\mathrm{m})\end{array}$ \\
\hline CUK & 1500 & 24 \\
\hline BOOST & 1280 & 20 \\
\hline BUCK-BOOST & 1270 & 19.7 \\
\hline
\end{tabular}

- From the above table it is observed that the CUK converter is operated at almost the rated speed and torque irrespective of the changes in the input solar energy as the Cuk converter has wide MPPT operating range.

- The boost converter has voltage as well as current ripples due to which the speed and torque is not as desired. The other drawback is that it doesn't have wide operating range of MPPT.

- The buck-boost converter has voltage as well as current ripples due to which the control in the voltage across the bus is difficult and employing the MPPT control algorithm is also difficult due to the input current ripples.

Therefore from the above discussion it can be concluded that among these three different converters CUK converter is more advantageous. Employing the CUK converter makes the system reliable and also efficient.

\section{REFERENCES}

1. Bhim Singh, Anjana kumar, and Rajan Kumar, "Solar Powered Water Pumping System Employing Switched Reluctance Motor Drive" IEEE Transactions on Industrial applications 2016, pp. 1-8.

2. A. K. Mishra and B. Singh, "Design of PV powered SR motor driven irrigation pumps utilizing boost converter," 2016 IEEE Uttar Pradesh Section International Conference on Electrical, Computer and Electronics Engineering (UPCON), Varanasi, India, 2016, pp. 264-268

3. B. Singh and A. K. Mishra, "SPV array powered SC buck-boost converter fed SRM drive for water pumping," 2016 International Conference on Emerging Trends in Electrical Electronics \& Sustainable Energy Systems (ICETEESES), Sultanpur, 2016, pp 267-273.

4. A. K. Mishra and B. Singh, "Solar photovoltaic array dependent dual output converter based water pumping using Switched Reluctance Motor drive," 2016 IEEE 6th International Conference on Power Systems (ICPS), New Delhi, 2016, pp. 1-6.

5. S. G. Malla, C. N. Bhende, and S. Mishra, "Photovoltaic based water pumping system," Int. Conf. Energy, Automation Signal (ICEAS), 28-3 Dec. 2011, pp. 1-4.

6. S. Belliwali, A. Chakravarti and A.B. Raju, "Mathematical modelling and simulation of directly coupled PV water pumping system employing Switched Reluctance Motor,' IEEE PES Innovative Smart Grid Technologies - India (ISGT India), 2011, pp.no.386-390, 1-3 Dec. 2011.

7. Karami, N., Moubayed, N., Outbib, R.: 'General review and classification of different MPPT techniques’, Renew. Sustain. Energy Rev., 2017, 68, (1), pp. 1-18.

8. Mohan, N., Undeland, T. M., Robbins, W. P.: 'Power electronics: converters, applications and design' (John Wiley \& Sons Inc., New Delhi, India, 2010, 3rd edn.).

9. T. J. E. Miller, "Switched Reluctance Motor and their control" in
Oxford:Magna Physics Publishing and Clarendon Press, 1993.

10. N. Femia, G. Petrone, G. Spagnuolo, M. Vitelli, "Optimizing duty-cycle perturbation of P\&O MPPT technique", IEEE 35th Annual Power Electronics Specialists Conference, vol. 3, pp. 1939-1944, 20-25 June 2004.

11. Mohan, N., Undeland, T. M., Robbins, W. P.: 'Power electronics: converters, applications and design' (John Wiley \& Sons Inc., New Delhi, India, 2010, 3rd edn.).

12. R. Krishnan, "SRM modeling simulation and analysis design and applications" in , CRC Press, 2001

\section{AUTHORS PROFILE}

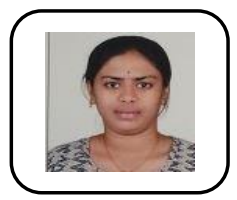

T. Sai Rakshitha student at EEE department pursuing master's at VNRVJIET, Hyderabad in Power Electronics and interested in research work on power electronic converters and renewable energy sources.

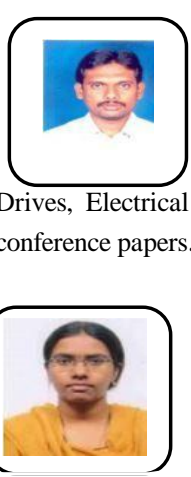

E. Shiva Prasad is working as an assistant professor at VNR VJIET in electrical department. He pursued B.Tech in Electrical Engineering from SSIT in the year 2005 and M.Tech in the year 2007 in power electronics. His research interests are in Electro mechanics, Power Systems, Control Systems \& Power electronics and Drives, Electrical Circuits and Network Theory. He has published several conference papers.

K. Sravani is Assistant professor at EEE department, VNRVJIET ,Hyderabad . Graduated in the year 2012, post - graduation in power electronics in the year 2014. Her research interests are in Power Electronic Driver Applications, Applications based on renewable energy source with control of the system, UPS device applications She is working on projects mainly consisting of renewable sources of energy. 